\title{
PSEUDO ALMOST PERIODIC SOLUTIONS FOR EVOLUTION EQUATIONS AND APPLICATIONS
}

\author{
Mounir Ben Salah ${ }^{1}$ \\ ${ }^{1}$ Universite de Kairouan
}

August 4, 2020

\begin{abstract}
In this paper we investigate the existence of the pseudo almost periodic solutions for evolution equations by using Schaffer theorem. Moreover, we study the exponential stability of these solutions. As application, we give examples in biology models to illustrate the main results of this work.
\end{abstract}

\section{Hosted file}

Ben Salah M.pdf available at https://authorea.com/users/348511/articles/473792-pseudo-almostperiodic-solutions-for-evolution-equations-and-applications 